(2) Open Access Full Text Article

\title{
In situ Management of Large Upper Ureteric Calculus by Mini-Percutaneous Nephrolithotomy in the Era of Retrograde Intrarenal Surgery
}

This article was published in the following Dove Press journal: Research and Reports in Urology

\author{
Sanjay Prakash Jayaprakash (iD) \\ Mathisekaran Thangarasu (iD) \\ Nitesh Jain \\ Sandeep Bafna (D) \\ Rajesh Paul \\ Apollo Main Hospitals, Chennai, India
}

Correspondence: Sanjay Prakash Jayaprakash

Apollo Main Hospitals, Chennai, India

Tel +9l 9894433567

Email sanprinarch@gmail.com
Purpose: The aim of the study is to demonstrate the ease and success of in situ management of large upper ureteric stones with mini percutaneous nephrolithotomy (PCNL).

Methods: This was a prospective observational study conducted in the Department of Urology between January 2018 and June 2019. All patients underwent standard prone mini PCNL with 15Fr amplatz with 80 cases of fluoroscopic and 12 cases of ultrasound guided access. In three cases of tortuous ureters, wire was passed via retrograde catheter and retrieved via amplatz to straighten the ureter. Calculi fragmented with laser.

Results: A total of 77 patients were included in this study, 62 unilateral and 15 bilateral cases ( 92 renal units). The mean age was $45.4 \pm 13.7$ years (range 17-71), male to female ratio was $61: 16$, the disease laterality (left: right) was $28: 34$. The mean stone size was 17.6 $\pm 1.4 \mathrm{~mm}$. Mean operative time was $22.4 \pm 1.5 \mathrm{~min}$. $88 \%$ patients were discharged as day care. Complication rate was $6.5 \%$, three patients had transient fever and two patients had distal migration of small fragments and they were extracted at the time of DJ stent removal by rigid ureteroscopy $(100 \%)$.

Conclusion: We conclude that it is easy and effective to deal with large upper ureteric calculus when it is in a fixed position. In situ management of large upper ureteric calculus by mini-PCNL can be done safely and effectively as it is a fast procedure, prevents unnecessary manoeuvres, less complication rates and has good stone clearance rates.

Keywords: hydroureteronephrosis, laser lithotripsy, upper ureter stones, urolithiasis

\section{Introduction}

Urinary stone disease/urolithiasis is a common cause of morbidity and it is a recurrent disorder with a lifetime recurrence risk of $50 \%{ }^{1}$ It is considered as a disease with significant socioeconomic impact influencing quality of life. The development of minimally invasive surgical techniques for treating renal stones has largely revolutionized due to various technologic advances in fibre optics, better radiographic imaging, and various types of lithotripsy modalities. Stones in the upper ureter can be accessed via retrograde, antegrade approaches and by laparoscopy. Extracorporeal shock wave lithotripsy (ESWL), rigid ureteroscopy (R-URS) and lithotripsy (R-URSL) and flexible ureteroscopy (RIRS) are the retrograde techniques. Antegrade approaches are the percutaneous nephrolithotomy (PCNL) and minipercutaneous nephrolithotomy (MPCNL). Pushback PCNL is a combination of retrograde followed by antegrade procedure. ${ }^{2,3}$ The dilemma in choosing the best technique for the patient depending on its size and location still exists. 
The main difficulty that would be encountered with retrograde techniques is proximal migration of stone into a dilated system and subsequent difficulty in breaking the stone as the stone keeps moving continuously. This can be successfully overcome with antegrade techniques where the stone is accessed when it is in a fixed location.

In the present study, our aim is to demonstrate the ease and success of in situ (at its primary location) management of large upper ureteric stones with mini PCNL.

\section{Materials and Methods}

After obtaining ethical committee clearance, this prospective observational study was conducted in the Urology Department for a period of one and half years (January 2018 to June 2019). All consecutive patients (presenting with pain abdomen/burning micturition/haematuria) diagnosed with large upper ureteric calculus (more than or equal to $12 \mathrm{~mm}$ ) initially detected on ultrasound kidney ureter bladder (KUB) and confirmed with unenhanced helical CT KUB were included in the study.

\section{Inclusion Criteria}

1. Stones located between the pelviureteric junction and the upper border of the fourth lumbar vertebra. ${ }^{4}$

2. Functional renal units.

\section{Exclusion Criteria}

1. Uncorrected Coagulopathy.

2. Associated pyelonephritis/Urosepsis.

3. Concomitant renal calculi.

4. Upward migration of stone while placing the retrograde ureteric catheter (RGC).

Preoperatively, patients were evaluated by complete blood count, renal function test, coagulation profile, urine routine test, urine culture and sensitivity test. DMSA scan was performed when the functional status of the renal unit was questionable (severe HDN with gross thinning of parenchyma or a shrunken/atrophic kidney). Patients having positive urine $\mathrm{C} / \mathrm{S}$ were treated with appropriate IV antibiotics according to antibiogram till urine was sterile. Cardiac evaluation was done for patients aged 60 years and above. Anaesthesia evaluation and fitness obtained with all investigations. In all cases informed consent was obtained from the patients participating in the study. The demographic and clinical characteristic of the patients were recorded. Informed consent from all patients and Institutional ethical committee clearance (Institutional
Ethics Committee - Clinical Studies, Apollo Hospitals, Chennai) were obtained. The study was conducted in accordance with the Declaration of Helsinki.

Single dose of IV Antibiotic was administered prophylactically to all patients at the time of induction. The standard prone mini-PCNL procedure was performed under general anaesthesia. An open-ended 5-Fr ureteric catheter was placed (unilateral or bilateral) till the point of first resistance by cystoscopy with the patient in the lithotomy position. After securing the catheter to a Foley catheter (16-Fr), the patient was turned to the prone position. Percutaneous access was obtained by the placement of an 18-gauge access needle into the intended calyx (most often the middle calyx) by $30^{\circ}, 0^{\circ}$ Bull's eye technique under real-time X-ray guidance with the help of retrograde pyelography. In cases where the contrast agent cannot transit into the PCS due to complete obstruction puncture was made under ultrasound guidance. A 0.035 inch floppytipped terumo guide wire was passed through the needle into the collecting system. The access needle was then removed and the skin and fascia were incised. Nephrostomy tract dilation was done with serial dilators (Cooks) through the guide wire up to 16-Fr and 15-Fr mini amplatz sheath was placed. In cases of tortuous ureters, retrograde wire was passed via $\mathrm{RGC}$ and retrieved via amplatz to straighten the ureter. Calculus identified with 12-Fr mini Storz nephroscope, dusted by laser lithotripsy (Sphinx 30 Watt holmium laser). Most stone fragments could be flushed out along with the backflow through the amplatz sheath, while few remaining big fragments needed extraction with stone forceps. At the end of the procedure, a 5-Fr double-J (DJ) stent and puncture site infiltrated with $0.25 \%$ injection bupivacaine for pain relief. A 14-Fr nephrostomy tube was routinely placed and clamped (for re-access if necessary). Patients were discharged with oral antibiotics and analgesics. Nephrostomy tube was removed at discharge and foley on post-operative day (POD) 1 or 2 as outpatient.

On postoperative day one, a plain X-ray KUB/USG KUB (for translucent stones) was done to assess stone clearance. "Stone-free" was defined as no residual stones or fragments $\leq 3 \mathrm{~mm}$ detected on plain X-ray KUB/USG KUB, as fragments $\leq 3 \mathrm{~mm}$ pass spontaneously. ${ }^{4,5}$ Total procedure time was calculated from cystoscopy and RGC placement to placement of the nephrostomy tube. Total operative time was calculated from puncture to tube placement. ${ }^{5}$ Patients were either discharged as day care $(<24$ hours $)$ or hospitalised for 24 hours for logistic 
purposes. Complications were graded as per Revised Clavien Dindo Classification System (RCCS). ${ }^{6}$

\section{Follow-Up}

All patients were followed up at six weeks and the DJ stent was removed successfully.

\section{Statistical Analysis}

The recorded data was compiled and entered in a spreadsheet (Microsoft Excel) and then exported to data editor of SPSS Version 20.0 (SPSS Inc., Chicago, Illinois, USA). Continuous variables were summarized in the form of means and standard deviations and categorical variables were summarized as percentages.

\section{Results}

Total number of patients presented consecutively were 79 . Two patients were excluded in view of upward migration while passing RGC. The study comprised of 77 patients with proximal ureteric calculi with hydronephrotic kidneys. Among them 62 were unilateral and 15 were bilateral cases, a total of 92 renal units. Demographically the mean age was $45.4 \pm 13.7$ years (range 17-71), male to female ratio was 61:16, the disease laterality (left: right) was $28: 34,15$ were bilateral cases.

All the cases were performed by a single surgeon with an experience of nearly 12 years in the field. All patients underwent standard prone mini PCNL with 15-Fr amplatz. In 80 renal units access was achieved with fluoroscopic guidance and 12 renal units USG guided access were obtained (RGP cannot be done as the contrast agent cannot transit into the PCS due to complete obstruction). In three cases of tortuous ureters, where retrograde wire was passed via RGC and retrieved via amplatz to straighten the ureter.

Mean stone size was $17.6 \pm 1.4 \mathrm{~mm}$. In 90 cases stone clearance was achieved with a single puncture and 2 cases needed double puncture due to tortuous ureter and migrated fragment. Stone free rate following single procedure was $98 \%$. Mean procedure time in unilateral cases was $52.9 \pm 5$ minutes and bilateral cases was $71 \pm 4.6$ minutes. The mean operative time for unilateral cases was $22.4 \pm 1.5$ minutes and bilateral cases was $43.2 \pm 2.4$ minutes. $88 \%$ were discharged as day care and $12 \%$ were discharged after 24 hours due to logistic purposes (Table 1). Our overall complication rate was $6.5 \%$, three patients developed transient fever responding to oral antipyretics (RCCS Grade I, 3.9\%) and two patients had distal migration of small fragments (RCCS IIIb, 2.6\%) detected on POD1 X-ray KUB. Both of
Table I Results

\begin{tabular}{|c|c|}
\hline $\begin{array}{l}\text { Total no. of patients } \\
\text { Total no. of renal units }\end{array}$ & $\begin{array}{l}77 \\
92\end{array}$ \\
\hline \multicolumn{2}{|l|}{ Laterality } \\
\hline Unilateral & 62 (R: $L-34: 28)$ \\
\hline Bilateral & 15 \\
\hline Mean Age & $45.4 \pm 13.7$ years \\
\hline Male to Female ratio & $61: 16$ \\
\hline Mean stone size & $17.6 \pm 1.4 \mathrm{~mm}$ \\
\hline \multicolumn{2}{|l|}{ Mean procedure time } \\
\hline Unilateral & $52.9 \pm 5$ minutes \\
\hline Bilateral & $7 I \pm 4.6$ minutes \\
\hline \multicolumn{2}{|l|}{ Mean operative time } \\
\hline Unilateral & $22.4 \pm 1.5$ minutes \\
\hline Bilateral & $43.2 \pm 2.4$ \\
\hline \multicolumn{2}{|l|}{ No of Punctures } \\
\hline \multicolumn{2}{|l|}{ Single } \\
\hline Calyx - Upper & 11 \\
\hline Middle & 52 \\
\hline Lower & 27 \\
\hline Multiple & 2 \\
\hline \multicolumn{2}{|l|}{ Discharge } \\
\hline Day care & $88 \%$ \\
\hline 24 hours & $12 \%$ \\
\hline Stone clearance & $98 \%$ \\
\hline Complication rate & $6.5 \%$ \\
\hline
\end{tabular}

them underwent diagnostic ureteroscopy and stone extraction at the time of DJ stent removal. At six weeks follow up, DJ stent was removed in all patients without complications and stone free rate was $100 \%$.

\section{Discussion}

Ureteric calculi are commonly encountered in day to day practise. Large diameter stones $(>10 \mathrm{~mm})$ are stranded easily in the upper ureter posing a serious threat to the function of the kidney on the affected side (hydronephrosis, renal damage). ${ }^{7}$ Timely effective treatment is the key to preventing irreversible damage. Over the past few decades, lifestyle and dietary habits have undergone a change in India increasing the incidence of stone formation.

We opted for mini PCNL over other techniques due to the following reasons:

ESWL does not assure complete relief of obstruction as evidenced by Park et al achieving a $72.4 \%$ stone-free rate after a single ESWL session, but the rate decreases to $42 \%$ when the stone is $>1 \mathrm{~cm}^{8}$ It is often associated with 
prolonged attacks of pain during stone passage, flank soreness and repeated treatment $(60 \%)$ in a substantial fraction of patients. $^{7}$

Stone clearance rates of semi rigid ureteroscopy (R-URS) is only $68-76 \%$ and its clearance rates decrease with an increase in the size of the stones. ${ }^{9,10}$ Upward migration of ureteral stones or big fragments is the main reason for failure in R-URS and the reported incidence ranges from $28 \%$ to $60 \%$. ${ }^{11}$ Although some studies used an anti-retropulsion device such as retrieval basket during rigid URS, the large stones did not allow additional space for passing the wire of the device. Moreover, the edematous and inflammatory mucosa impede visualization of the stones, which makes it difficult to perform the lithotripsy and increased chances of ureteric injuries. ${ }^{12}$ Hence the incidence of using adjunct procedures (ESWL/ PCNL) are high to achieve complete clearance.

Use of RIRS to remove ureteral stones requires highly skilled surgeons to reduce the ureteral injury and manipulation of scopes in a dilated system. ${ }^{13}$ Availability of the scopes is also a major drawback. Larger stones require staged procedures and longer operative times. Timeconsuming technical manoeuvring is required in RIRS for stone fragmentation, ie, placement of stones in a favourable calyx to avoid strain on the deflection mechanism and risk of laser fibre damaging the scope. Moreover, after fragmentation stones are not retrieved and left within the kidney. Stone free rates are significantly superior in mini PCNL when compared to RIRS and it is shown in the studies by $\mathrm{Gu}$ et al, $2013^{14}$ (93.3\% vs $41.4 \%$ at 2 weeks, $100 \%$ vs $89.7 \%$ at 1 month), Jiao et al, $2019^{15}$ $(84.48 \%$ vs $72.72 \%)$ and Chen et al, $2020^{16}$ (RR: 1.07 ; 95\% CI:1.03, 1.12; p = 0.0004). Operative times of RIRS were also longer $(90.40 \pm 31.29 \mathrm{~min}$ vs $105.56 \pm 45.76$ $\min ; \mathrm{p}<0.05,49.3 \pm 11.7 \min$ vs $67.2 \pm 17.3 \min , \mathrm{p}<$ 0.001 , respectively) with comparable stone burden. ${ }^{15,17}$

Pushback PCNL (PBPCNL) is still a very common practise in many parts of India. Disadvantages noted with it are multiple manoeuvres, longer operating times, migration of stone fragments into multiple calyces needing multiple punctures or ESWL for stone clearance and subsequent complications, costs incurred due to longer operating times are certain drawbacks of PBPCNL. In a dilated system we have no control into which calyx the stones migrate especially when into upper calyx which needs supracostal/multiple punctures for stone clearance.

As per our institute policy, we do laparoscopic ureterolithotomy for stones measuring more than $3 \mathrm{~cm}$. Since in
Table 2 Comparison of Mini PCNL Studies

\begin{tabular}{|l|l|l|l|l|}
\hline Variables & $\begin{array}{l}\text { Present } \\
\text { Study }\end{array}$ & $\begin{array}{l}\text { Long } \\
\text { et al }\end{array}$ & $\begin{array}{l}\text { Najar } \\
\text { et al }^{4}\end{array}$ & $\begin{array}{l}\text { Murthy } \\
\text { et al }^{5}\end{array}$ \\
\hline $\begin{array}{l}\text { Stone Clearance } \\
\text { Rate at discharge }\end{array}$ & $98 \%$ & $95.7 \%$ & $86.7 \%$ & $100 \%$ \\
\hline $\begin{array}{l}\text { Mean Operative } \\
\text { Time (unilateral) }\end{array}$ & $22 \mathrm{~min}$ & $37 \mathrm{~min}$ & $62 \mathrm{~min}$ & $36 \mathrm{~min}$ \\
\hline Hospital Stay & $\begin{array}{l}88 \%-\text { Day care } \\
12 \%-24 \mathrm{hrs}\end{array}$ & 86 hours & 67 hours & 54 hours \\
\hline Complications & $6.5 \%$ & $23.1 \%$ & $25 \%$ & 0 \\
\hline
\end{tabular}

our series we encountered a mean size of $17.6 \pm 1.4 \mathrm{~mm}$, we did not prefer laparoscopy.

In our study mini PCNL (Table 2) was used to treat large upper ureteric calculi. The commonest age group affected in our study is between 31-50 years with a mean age of 45.4 \pm 13.7 years similar Najar et al and Murthy et al. ${ }^{4,5}$

We have compared our study results with three recent mini PCNL studies treating proximal upper ureteric stones - Long et $\mathrm{al}^{7}{ }^{7}$ Najar et $\mathrm{al}^{4}$ and Murthy et $\mathrm{al}^{5}$ respectively. The main aim of a urologist is to achieve a $100 \%$ stone clearance rate. In our study, we were able to achieve $98 \%$ stone free rate with mini PCNL (90 units with single puncture and 2 units with double punctures) in a single setting. However, in 2 patients $(2 \%)$ who had distal migration of stone, fragment was removed by diagnostic ureteroscopy at the time of DJ stent removal. Hence we were able to achieve $100 \%$ stone clearance, a significant high success rate. With single puncture Long et al was able to achieve a success rate of $95.7 \%{ }^{7}$ At discharge Najar et al achieved a success rate of $86.7 \%$, which improved to $96.7 \%$ by spontaneous expulsion of stones at 1 month. The remaining 3.3\% (two patients) had stone fragments migration and they used R- URS for its removal. ${ }^{4}$ Murthy et al boasts $100 \%$ stone free rate with single puncture. ${ }^{5}$

In our study, shorter mean operative time (22 minutes for unilateral and 43 minutes for bilateral) is noted when compared to other studies (unilateral only) of $37 \mathrm{mins}, 62$ mins and 36 mins respectively. ${ }^{4,5,7}$

All our patients were evaluated as outpatients and patients get admitted on the day of surgery. In our series, $88 \%(n=67)$ of the patients were discharged as day care with urinary catheter and the remaining $12 \%$ were discharged by 24 hours for logistic purposes. Hospital stay is significantly shorter when compared to similar studies, 86 hours (range 2-6 days), 67 hours and 54 hours respectively., ${ }^{4,5}$ 
We noted minimal complications (immediate/early postoperative) in our study, our overall complication rate was $6.5 \%$, three patients developed transient fever responding to oral pyretic medication (Clavien Dindo Grade I, 3.9\%) and two patients had distal migration of small fragments (Clavien Dindo Grade IIIb, 2.6\%) detected on postoperative $\mathrm{X}$-ray KUB. The overall complication rates seen in Long et al was $23.1 \%$ (bleeding intraoperatively -6 patients, transient fever $>38.5{ }^{\circ} \mathrm{C}-24$ patients, and hematuria $>36$ $\mathrm{h}-14$ patients), in Najar et al was $25 \%$ (post-operative fever - five patients, prolonged hematuria - four patients, blood transfusion - one patient and thoracic complications - one pneumothorax and three hydrothoraxes), no complications were noted in the Murthy et al study. ${ }^{4,5,7}$ Since we have taken RCCS classification, distal stone fragments migration is also taken as a complication of Grade IIIb whereas other studies do not mention them as the same.

Our experiences are the following:

(a) It is easy to access and break the stone when it is at a fixed site.

(b) Mini PCNL can be done successfully as a day care procedure in treating upper ureteric stones.

(c) A thorough preoperative evaluation and planning can effectively reduce the chance of complications.

(d) Skilled teamwork is very helpful in shortening the operative time, achieving good success rates and post-operative patient recovery.

\section{Conclusion}

We conclude that it is easy and effective to deal with large upper ureteric calculus when it is in a fixed position. In situ management of large upper ureteric calculus by miniPCNL can be done safely and effectively as it is a fast procedure, prevents unnecessary manoeuvres, less complication rates and has good stone clearance rates.

\section{Acknowledgment}

Institution where the work was carried out: Department of Urology, Apollo Main Hospitals, Chennai, Tamil Nadu, India.

\section{Funding}

No financial aid provided.

\section{Disclosure}

The authors report no conflicts of interest for this work.

\section{References}

1. Prezioso D, Di Martino M, Galasso R, Iapicca G. Laboratory assessment. Urol Int. 2007:79(SUPPL. 1):20-25. doi:10.1159/000104437

2. Preminger GM, Assimos DG, Lingeman JE, Nakada SY, Pearle MS, Wolf JS. Chapter 1: AUA guideline on management of staghorn calculi: diagnosis and treatment recommendations. J Urol. 2005;173 (6):1991-2000. doi:10.1097/01.ju.0000161171.67806.2a

3. Smith AD, Lange PH, Fraley EE. Applications of percutaneous nephrostomy. New challenges and opportunities in endo-urology. J Urol. 1979;121(3):382. doi:10.1016/S0022-5347(17)56797-X

4. Najar FA, Mir BY, Mir MA. Safety and efficacy of mini-percutaneous nephrolithotomy in the treatment of large impacted proximal ureteral stones. Int Surg J. 2019;6(2):518. doi:10.18203/2349-2902.isj20190395

5. Murthy NR, Kumar JS, Tej PR, Srinivas B, Swapnil B, Reddy YA. Role of mini PCNL in the treatment of renal and upper ureteric calculus. J Evol Med Dent Sci. 2019;8(3):170-173. doi:10.14260/ jemds $/ 2019 / 37$

6. Elkoushy MA, Luz MA, Benidir T, Aldousari S, Aprikian AG, Andonian S. Clavien classification in urology: is there concordance among post-graduate trainees and attending urologists? J Can Urol Assoc. 2013;7(5-6 JUN):179-184. doi:10.5489/cuaj.505

7. Long Q, Guo J, Xu Z, et al. Experience of mini-percutaneous nephrolithotomy in the treatment of large impacted proximal ureteral stones. Urol Int. 2013;90(4):384-388. doi:10.1159/000343668

8. Park H, Park M, Park T. Two-year experience with ureteral stones: extracorporeal shockwave lithotripsy $\mathrm{v}$ ureteroscopic manipulation. $J$ Endourol. 1998;12(6):501-504. doi:10.1089/ end.1998.12.501

9. Galal EM, Anwar AZ, Fath El-Bab TK, Abdelhamid AM. Retrospective comparative study of rigid and flexible ureteroscopy for treatment of proximal ureteral stones. Int Braz J Urol. 2016;42 (5):967-972. doi:10.1590/S1677-5538.IBJU.2015.0644

10. Karadag MA, Demir A, Cecen K, et al. Flexible ureterorenoscopy versus semirigid ureteroscopy for the treatment of proximal ureteral stones: a retrospective comparative analysis of 124 patients. Urol J. 2013;11(5):1867-1872.

11. Chow GK, Patterson DE, Blute ML, Segura JW. Ureteroscopy: effect of technology and technique on clinical practice. $J$ Urol. 2003;170 (1):99-102. doi:10.1097/01.ju.0000070883.44091.24

12. Wang Q, Guo J, Hu H, et al. Rigid ureteroscopic lithotripsy versus percutaneous nephrolithotomy for large proximal ureteral stones: a meta-analysis. PLoS One. 2017;12(2).

13. Berardinelli F, Cindolo L, De Francesco P, et al. The surgical experience influences the safety of retrograde intrarenal surgery for kidney stones: a propensity score analysis. Urolithiasis. 2017;45(4):387-392. doi: 10.1007/s00240-016-0919-0

14. Gu XJ, Jian Lin L, Yan X. Treatment of large impacted proximal ureteral stones: randomized comparison of minimally invasive percutaneous antegrade ureterolithotripsy versus retrograde ureterolithotripsy. World J Urol. 2013;31(6):1605-1610. doi:10.1007/s00345-013-1026-2

15. Jiao B, Lai S, Xu X, Zhang M, Diao T, Zhang G. The efficacy of flexible ureteroscopy lithotripsy and miniaturized percutaneous nephrolithotomy for the treatment of renal and proximal ureteral calculi of $\leq 2 \mathrm{~cm}$. Medicine (Baltimore). 2019;98(11):e14535. doi:10.1097/MD.0000000000014535

16. Chen Y, Wen Y, Yu Q, Duan X, Wu W, Zeng G. Percutaneous nephrolithotomy versus flexible ureteroscopic lithotripsy in the treatment of upper urinary tract stones: a meta-analysis comparing clinical efficacy and safety. BMC Urol. 2020;20(1):1-12. doi:10.1186/ s12894-020-00677-4

17. Zhang Y, Yu CF, Jin SH, Zhu H, Na YQ. A prospective comparative study between minimally invasive percutaneous nephrolithotomy in supine position and flexible ureteroscopy in the management of single large stone in the proximal ureter. Urology. 2014;83 (5):999-1002. doi:10.1016/j.urology.2013.11.034 


\section{Publish your work in this journal}

Research and Reports in Urology is an international, peer-reviewed, open access journal publishing original research, reports, editorials, reviews and commentaries on all aspects of adult and pediatric urology in the clinic and laboratory including the following topics: Pathology, pathophysiology of urological disease; Investigation and

Submit your manuscript here: https://www.dovepress.com/research-and-reports-in-urology-journ treatment of urological disease; Pharmacology of drugs used for the treatment of urological disease. The manuscript management system is completely online and includes a very quick and fair peer-review system, which is all easy to use. Visit http://www.dovepress.com/ testimonials.php to read real quotes from published authors. 